\title{
Bird in the wire: Creativity, resistance, networked citizenships
}

Digital Creativity

\section{Sam Cleeve}

Media and Cultural Studies, Birmingham City University, West Midlands, UK

Flat 5, 120 Palatine Road, Manchester, M20 3ZA

mob: $+44(0) 7399620734$

email: sam.cleeve@mail.bcu.ac.uk; sw.cleeve@gmail.com

Bio: Sam Cleeve is a doctoral candidate at the Birmingham Centre for Media and Cultural Studies (BCMCR) at Birmingham City University. With a background in musicology, his research follows two general trajectories: music and digital culture, with a special emphasis on the spatiotemporal dimensions of emergent technologies such as virtual reality, and post-structuralist approaches to musical analysis, usually directed toward twentieth-century art, experimental, and popular musics. Previous work in the latter category has been published by Perspectives of New Music. He holds degrees in musicology from the University of Oxford (MSt) and the University of Birmingham (BMus).

Words (inclusive of references): 6,028 
Abstract: This paper contemplates the extent to which online music making and sharing practices can be understood as acts of creative citizenship. While the digital is often lauded as mechanism by which citizens may engage creatively with local or national communities, this paper contends that it may equally represent a means for disengagement with those groups, by instead facilitating participation in the transnational, diasporic communities that have long prospered on the Internet. Possible motivations for this are multifarious and context-dependent, but often signify an act of resistance: against artistic and commercial institutions, against creatively oppressive states, against the cultural isolation of an immediate environment. This paper holds that this type of digitally-mediated creative engagement-that which arises as a specific reaction to a perceived inadequacy in one's civic life-might be best understood through the lens of creative citizenship. In order to assess the relationship between online creative communities and their offline counterparts, it employs the framework of 'networked individualism' (Castells 2001; Wellman et al. 2006; Raine and Wellman 2012), and contextualises its ideas by referring to recent studies in online amateur music-making in Iran, where the digital is often regarded as a way of circumnavigating the creative oppression of the state.

Keywords: citizenship, online communities, networked individualism, creativity, music.

\section{Introduction}

In 2013, prominent German pianist and composer Nils Frahm uploaded a recording-a droning, ambient piece of music awash with harmonics and reverb titled 'I don't belong here'-to his SoundCloud account, a page followed by close to two million. ${ }^{1}$ What made this ostensibly unremarkable manoeuvre somewhat more unusual was that 'I don't belong here' was written not by Frahm, but by Mohammad Moussavi, an Iranian fan and relative unknown. By his own admission, Frahm had been motivated to share the music more widely having received it from Moussavi accompanied by a note explaining the turbulence of Iran's musical culture. "Here in Iran", Moussavi wrote, "[there] is no way to publish these kind of music, Iran is a Muslim country and music is called HARAM here (means music is a sin). so what we are all working is ilegal here. but this lifestyle is the only that i can \& want to do [sic]".2 At the time of writing, 'I don't belong here' had been played over one hundred thousand times, with a dialogue having opened up between Moussavi and supportive Soundcloud users from around the world. In spite of Iran's cultural imperialism, Moussavi was able to seek refuge in the diasporic, transnational community gathered around Frahm's SoundCloud page. Where his immediate civc life proved lacking, the Internet offered a convenient, accessible supplement.

This paper contemplates the extent to which online music making and sharing practices can be understood acts of creative citizenship, with a special emphasis on instances in which those creative practices represent an escape from, rather than engagement with, the immediate civic life of the practitioner. Of course a wealth of scholarship in this area has ably noted the changing modes of civic engagement brought about by digital media and social networks, and the new creative routes to civic and political participation that have

\footnotetext{
${ }^{1}$ SoundCloud is an online music streaming platform and community; it describes itself as 'the world's leading social sound platform where anyone can create sounds and share them everywhere. See: https://soundcloud.com/pages/ contact.

${ }^{2}$ https://soundcloud.com/nils_frahm/i-dont-belong-here-by.
} 
emerged as a result. Bennett (2008; Bennett, Wells and Freelon 2011), for instance, contrasts 'dutiful' and 'actualizing' models of citizenship. The former represents a conventional, historic model of civic life in which individuals participate... through organised groups, from civic clubs to political parties, while becoming informed via the news, and generally engaging in public life out of a sense of personal duty' (Bennett, Wells and Freelon 2011, 838). Meanwhile the latter 'enables us to think about a generational shift away from taking cues as members of groups or out of regard for public authorities (opinion leaders, public officials, and journalists), and toward looser personal engagement with peer networks that pool (crowd source) information and organise civic action using social technologies that maximise individual expression' (Bennett, Wells and Freelon 2011, 839). The 'actualizing' model, he argues, affords 'spontaneous and creative forms of collective expression' (Bennett 2008, 2); 'creative and expressive opportunities for civic engagement' (Bennett, Wells and Freelon 2011, 851). Elsehwere, boyd's (2007) discussion of 'networked publics' contains an implicit distinction between 'unmediated' and 'mediated' versions of civic life: 'spaces and audiences that are bound together through technological networks (i.e. the Internet, mobile networks, etc.). Networked publics are one type of mediated public; the network mediates the interactions between members of the public.' Both scholars operate in dialogue with Jenkins's conception of 'participatory culture' (Jenkins et al. 2006, 2016), which contemplates a technologically-forged entanglement of civic participation and creative expression.

The creative dimensions of civic participation in the networked era have been more explicitly picked up in the scholarly discourse surrounding creative citizenship (Hargreaves and Hartley 2016; Ratto and Boler 2014). Within this context, creative and artistic practice is more often than not framed positively, as a constructive set of activities which both stem from, and feed back into, local, physical communities. This includes hyperlocal journalism (Harte 2013; Harte, Williams and Turner 2014); craft(ivism) (Levine and Heimerl 2008); community-led design (Sanders and Stappers 2014); documentary making (Rose 2014); gardening (DiSalvo 2014). The role of the digital-specifically those networked technologies embodied by the Internet-is curtailed to one simply adopted by, and serving, local, real-world communities. It strikes, however, that as much as the digital is being turned to as a mechanism by which to improve civic life, it also represents a way of escaping its various deficiencies. Not only might they serve as an apparatus for enabling interaction and creativity among a local community, but a means by which alternative social and creative relationships may be forged. In and of itself, of course, this is hardly any great revelation. But of special interest here are those creative practitioners who are motivated to seek out these digital opportunities as a result of living in culturally isolated, creatively oppressive, or otherwise dislocated local environments. This could well include (as this paper will explore in detail) musicians-like Moussavi-exercising their creativity online, whether as an act of resistance against oppressive governmental control, or simply against recording industries often perceived as hegemonic and impenetrable. In such cases, the opportunities afforded by digital (and/or social) media represent not simply a lowering of barriers toward certain kinds of creative and civic engagement, but the removal of blockades that would have otherwise been entirely insurmountable.

The purpose of this paper is not to present empirical or data-led research on online creative communities, but rather, by pave the way for a critical discussion about the plurality of ways in which online creative practices can be understood as enactments of citizenship. In part, at least, this will be achieved by surveying literature that addresses the notion of networked communities: globally distributed and culturally 
diverse groups assembled around a shared interest or concern, communities that exist (often solely) in digital spaces such as online fora, music streaming platforms, and crowd-funding websites. However, these ideas will also be contextualised with reference to various ethnomusicological studies that demonstrate the tangible praxis of such engagement, highlighting specific actors, collectives, and creative activities which might be said to constitute acts of creative citizenship.

\section{Online Communities and 'Networked Individualism'}

A number of central questions reside at the heart of contemporary thinking on the topic of virtual communities: to what extent can we, ontologically speaking, understand the real and the virtual as constituting separate domains of experience? To what extent can online interaction really constitute a community? What forms of organisation do they take? Can engagement in a virtual community really enact change in the offline world? In practice and for all day-to-day intents and purposes, of course, the world still exists as a collection of states and territories, demarcated by a series of oft-contested boundaries. And yet, signs that point toward the slow deterritorialisation of our world continue to emerge. Collaborative projects of any number of descriptions, whether professional or amateur, artistic or scientific, frequently transcend limitations of geographic location, cultural custom, and longitudinal divisions of time by connecting participants via global communication networks (Shirky 2008). The rise (and fall) of transnational, digital currencies is regular fodder for mainstream news outlets. ${ }^{3}$ Nation states are even beginning to show signs of loosening grips on resources: since 2014, Estonia has offered non-residents 'e-residency' (or 'virtual residency'), enabling access to banking, business, and legal services usually the reserve of nationals, the first scheme of its kind. ${ }^{4}$ Unsurprisingly, the sociological implications of networked communities have been the focal point of scholarship for some time, and it is the task of this section to note some pertinent work in this area.

Early work on cyber-communities conceptualised the digital as an autonomous space-i.e., a series of virtual locales within which groups and communities could converge-as opposed to a networked communication tool utilised and navigated by individual users. Analyses of Internet-driven sociality bore witness to the emergence of a "new form of community, brining people together on-line around shared values and interests, and creating ties of support and friendship that could also extend into face-to-face interaction" (Castells 2001, 119). By and large, this remained the case throughout much early, seminal work on the topic: The Virtual Community (Rheingold 1993), Life on the Screen (Turkle 1995), and The Rise of the Network Society (Castells 1996) all grounded their epistemologies in the existence of formal, 'strongly-knit' (to use Wellman's terminology), cohesive communities. Two trends have characterised academic thought since this initial period - the conceptualisation of the digital as a communicative tool, rather than social space, and a focal shift from the group to the individual:

\footnotetext{
${ }^{3}$ https://www.theguardian.com/technology/2016/may/03/bitcoin-tech-future-craig-wright-blockchain-transactions; http://www.bbc.co.uk/news/technology-35343561.
}

${ }^{4}$ https://e-estonia.com/e-residents/about/. 
... a fresh wave of digital optimism has more recently accompanied the advent of social media platforms such as Twitter, Facebook, Youtube, Wikis and the blogosphere. The distinctiveness of this second generation of internet democracy is the displacement of the public sphere model with that of a networked citizen-centred perspective providing opportunities to connect the private sphere of autonomous political identity to a multitude of chosen political spaces (Loader and Mercea 2011, 758).

In this new conception, an Internet user's digital DNA-indeed, their online identity-emerges from the unique combination of associations and alliances formed online, of which there are infinite and everincreasing possibilities. These associations are informal, multiplicitous, overlapping, and transient, less rigid and less concrete than those 'spatially-bounded' communities associated with traditional offline groups centred around family, work, religion, or pastime. Individual social media sites, such as Frahm's Soundcloud page, represent just one of innumerable digital nodes with which a user may connect.

The notion of "virtual communities," advanced by the pioneers of social interaction on the Internet... induced a major misunderstanding: the term "community", with all its powerful connotations, confused different forms of social relationship, and prompted ideological discussion between those nostalgic for the old, spatially bounded community and the enthusiastic supporters of Internet-enabled communities of choice (Castells 2001, 125).

If these inherently weak and transitory social connections are a troublesome aspect of networked communities (or 'publics', to borrow boyd's term), then they offer, as Castells notes above, a crucial consolation: choice. These informal relationships are identified and forged with a degree of voluntariness that would be incompatible with conventional social relationships such as those associated with family, neighbour(hood), workplace. Furthermore, these freely-associated weak ties clearly needn't comply to the same cultural codes, the same geographic restrictions, nor even the same linguistic frameworks-frankly, nor any restriction of space or time - to which users must usually abide in their offline lives. The sense of free will and volition which lies at the heart of digitally-mediated sociality has come to be referred to (initially by Wellman [1999, 2001; Wellman et al. 2006], since reiterated by Castells [2001]) as 'networked individualism':

We are now experiencing another transition, from place-to-place to person-to-person connectivity. Moving around with a mobile phone, pager, or wireless Internet makes people less dependent on place. Because connections are to people and not to places, the technology affords shifting of work and community ties from linking people-in-places to linking people wherever they are. It is I-alone that is reachable wherever I am: at a house, hotel, office, freeway or mall. The person has become the portal. ... The shift to a personalised, wireless world affords networked individualism, with each person switching between ties and networks. People remain connected, but as individuals rather than being rooted in the home bases of work unit and household (Wellman, 2002, 16).

Perhaps the necessary analytical step to understanding the new forms of social interaction in the age of the Internet is to build on a redefinition of community. ... Now, the dominant trend in the evolution of social relationships in our societies is the rise of individualism, in all its manifestations.... After the transition from the predominance of primary relationships (embodied in families and communities) to secondary relationships 
(embodied in associations), the new, dominant pattern seems to be built on what could be called tertiary relationships, or what Wellman calls "personalised communities," embodied in me-centred networks (Castells 2001, 127-128).

Again, this voluntariness-the sense that the Internet and associated communication technologies "are helping each individual to personalise his or her own community" (Wellman et al 2006, 17) -makes the digital an ideal vehicle for the formulation of associations beyond those which would be possible in users' conventional, day-to-day, offline lives and interactions. For loosely-associated creative communities, such as those informally gathered around music streaming, photo sharing, and video upload platforms, the benefit can seem to be one primarily of convenience (easily transcending issues of language or cultural custom, for example), or perhaps variety (affording access and exposure to a wide range of creative practices, styles, genres, etc.). But their significance increases by several orders of magnitude when one considers those creatives living in culturally isolated circumstances. For the geographically remote, culturally oppressed, or simply artistically detached creative practitioners, these kinds of informal, dynamic networked communities afford the opportunity to engage with others in way that would have been otherwise impossible.

In other instances, these on-line networks become forms of "specialized communities;" that is, forms of sociability constructed around specific interests. Since people may easily belong to several of these networks, individuals tend to develop their "portfolios of sociability," by investing differentially, at different points in time, in a number of networks with low entry barriers and low opportunity costs (Castells 2001, 132).

Castell and Wellman's 'networked individualism' resonates strongly with Bennett's 'actualizing' model of citizenship and with boyd's 'networked publics.' These individually-determined, highly personalised, networked social associations are a fundamental aspect of contemporary digital experience, and therefore something that should be of serious consideration with regards to creative citizenship. They have introduced a new, fundamentally self-directed component to the formation of one's civic identity, and crucially, one that needn't comply to the top-down hierarchical structures of any conventional, 'dutiful' model of citizenship. Thus, while the citizenship which this paper seeks to explore still ultimately belongs-as we will explore in more detail in the succeeding section - to the offline habitat of the user, the digital domain offers a means by which alternative versions of that citizenship might be enacted. By formulating relationships and ties that could not exist offline, creative practitioners are able to cut across geographical boundaries and cultural codes, practicing kinds of creativity, in styles, genres, materials that they would not be able to do in their immediate environment. Here we return to the initial conjecture of this paper. Creative citizenship is often thought to be the act of engaging and/or mobilising one's immediate, physical community through digitally-mediated creative practice. Might it not also be the ability to retract from one's immediate real-world community as a means of resistance when it proves faulty or lacking in some way, by, for example, seeking refuge within the dislocated, diasporic, self-selected communities of the Internet? The following section seeks to highlight specific examples of digitally-mediated creativity (in this instance, musical) toward which these broad questions might be directed. 


\section{Music-Making and the Iranian Digital Diaspora}

Iran's sustained period of cultural imperialism began after the Islamic Revolution of 1979, during which time a theocratic republic sought to 'cleanse the country of Western ideologies' by placing 'various cultural activities within an Islamic framework' (Rastovac 2009, 63). While the nuances of Shar'ia law and the ideology that governed these cultural and artistic policies cannot be covered in depth here, it has at certain points led to the banning of 'all concerts, and especially all radio or television broadcasts of foreign and Iranian, classical and popular music' (Youssefzadeh 2000, 38). Furthermore: 'the pāsdārān (revolutionary guards) organised raids to collect and destroy musical instruments. Playing music was forbidden. The bards who had participated in concerts and festivals under the old regime were summoned and cross-examined by the revolutionary authorities. Some of those who had performed at festivals, such as Karegar, died in obscurity' (Youssefzadeh 2000, 38). The ban on popular music in particular, notes Rastovac, 'consequently imbued this musical genre with an immense subversive power, and for young people in Iran listening to pop music became a form of resistance against the Islamic regime' (Rastovac 2009, 65). Since this time, Iran's cultural imperialism has advanced and receded depending on the cultural ideology of governmental authorities at any given time, but many restrictions, and indeed a general anti-musical sentiment, continues to exist in contemporary Iran:

Despite the increasing openness in the political and cultural spheres over the past decade, the conservative clerical lobby continues to challenge many of these changes. Music, particularly many styles of popular music, remains problematic for the government. Music is often caught within the power play between conservatives and reformists, both of whom are often deeply divided on the issue. ... Many of the restrictions established in the 1980s remain intact today: women are still restricted from performing as soloists, dancing or suggestive movement remains strictly forbidden in public, concerts or in music videos, musical instruments are not shown on television, and only religious music is allowed in public places on religious holidays (Rastovac 2009, 68-69).

It is perhaps unsurprising that, since the turn of the millennium, Iranians have begun circumnavigating the cultural censorship of the state by exercising their creativity among the dislocated milieux of online communities. Nooshin (2005), in her study of underground rock music practice in the country, refers in particular to a virtual competition held by arts and culture website tehranavenue.com, in which twenty-one Iranian rock bands partook during 2002 (the significance of this website is also noted in Elahi 2011). Each uploaded a single song, made available to the public for the duration of one month. During this time, the website registered '200,000 successful downloads from various cities and countries around the globe ... sixty percent of downloads were from outside the country' (Nooshin 2005, 476). The competition, and indeed the website, severed to gather an informal, transnational community around these musicians, providing a sense of collective identity that would have been almost impossible without the communicative network of the Internet. For them, it represented a simultaneously de-spatialised and global space of creative endeavour.

Further examples of such creative deployment of the digital in Iran can be found in the work and reportage of non-governmental organisation Freemuse. Freemuse is an 'independent international membership organisation advocating and defending freedom of expression for musicians and composers worldwide', which achieved Special Consultative Status with the United Nation's Economic and Social Council 
(ECOSOC) in 2012 (Freemuse 2008). The number of articles filed with the identifying tag 'Iran' on the Freemuse website exceeds one hundred - these articles account infringements that range from concerts to downloads to 'loud music', penalties for which include lashes, bans and capital punishment. For its utilisation of the Internet, however, one in particular stands out: "to the Iranian artist IO," the article reads, "the publishing of his album 'Music Hall 151' on 27 September 2007 is a victory over censorship. He could not have published it in Iran, but now instead, it is available world-wide via the internet" (Freemuse 2007).

IO (pronounced "eye-oh") is the stage name for Payman Abdali. His musical career in Iran was going well when in the summer of 1995 his concert 'Creation' in the Austrian Embassy was canceled by the Police just half an hour before the scheduled start time. This event had such a bad psychological effect on Payman that he stopped all musical activities for three years. ... Since 2001 Payman has simultaneously worked on two albums, ' 5 ' and 'Persian Robots', in which he experiments with a wide range of genres. Neither of the two got permission to be released in Iran due to the complicated procedures of the Ministry of Culture of the Islamic Republic (Freemuse 2007).

Elsewhere, Freemuse interview Gissoo Shakeri, an Iranian singer who has been living in Sweden since the Islamic revolution. "After the Islamic revolution, I couldn't sing; women's singing was banned, women's voices were not to be heard." Although Shakeri now enjoys artistic freedom in her adoptive homeland, she concedes that "in Iran, I am banned, except I can be heard clandestinely on the Internet. I have a website where people can download my songs for free. Many people contact me by email and tell me how happy they are that a woman artist has dedicated her life to this" (Freemuse 2006a).5 Around this time, however, Freemuse also posted a report indicating that the Internet itself has become a site of political struggle: "service providers have been told by Iran's Islamic government to restrict online speeds to 128 kilobytes a second and been forbidden from offering fast broadband packages, writes The Guardian. Banning high-speed internet makes it more difficult to download foreign music which the authorities blame for undermining Islamic culture among the younger generation" (Freemuse 2006b).

Informal networked communities such as these, gathered around websites and blogs, represent the only feasible means by which Iranian popular musicians can reach audiences outside of their homeland (or, in the case of Shakeri, inside), and their importance has not gone unnoticed by scholars in this area. This sentiment is one reiterated by Nooshin $(2008,77)$, who sees the Internet as a route towards "audiences outside Iran, both in the Iranian diaspora and non-Iranians', and confirmed by Rastovac $(2009,79)$, who states that 'with so few physical spaces to play music and distribute music, musicians in the underground scene have turned to the Internet and have created a virtual music community.' Furthermore, it is an opinion echoed by Shafaee $(2003,194)$, who regards these instances as part of a wider socio-political phenomenon: 'it appears that the Internet has allowed for the creation of a virtual society in the heart of Iran.'

In the absence of physical spaces in which to perform of the means by which to distribute music, the Internet is playing a crucial role in enabling musicians to communicate with each other and with audiences, effectively forming a virtual rock community. To quote from the lead singer of the band 127 , "the only club we have for

\footnotetext{
${ }^{5}$ Gisso Shakeri's official website: www.gissoo.com.
} 
playing is our website.” ... In comparison with existing means of circumnavigating central control—the black market or private concerts, for example-the Internet offered a relatively cheap, risk-free, and infinitely more flexible medium to access audiences, both inside and outside Iran (Nooshin 2005, 475).

In a more recent and wide-ranging overview of musical life in Iran, Siamdoust (2017) also notes the cultural significance of the Internet in mobilising artists within Iran, and reiterates the notion that it offers an 'alternative public sphere' (Siamdoust 2017,220), a means of circumnavigating state control. However, to a greater degree, Simdoust paints a cat-and-mouse picture involving those artists determined to utilise the Internet as a subversive space for civic protest through creative engagement and a government who, since 2009, has 'viewed these new media as a threat to the very foundations of the state and further tightened its grip on this sphere' (Siamdoust 2017, 217). The promise of the Internet's democratic potentials is perhaps fading: as digital literacy increases, the struggle between popular music's practitioners and those who police it perseveres in the networked sphere just as it does in physical spaces.

Nonetheless-and returning to Wellman and Castells-it is the flexibility, the multiplicity, and the individuality of these connections that make this form of subversive creative protest feasible at all. If virtual communities such as those referred to above possessed the formality of their offline equivalents, then not only would they likely lack the international reach and thus sense of insubordination that they possess, but their suppression by the state would be far more manageable. It is precisely their dynamism - the fact that they exist as temporary collections of networked individuals, as opposed to cohesive, permanent communitieswhich makes them such an ideal vehicle for circumnavigating governmental control. The musicians referred to above can be understood as enacting a self-directed vision of their citizenship through the networked publics of their chosen online communities, while also, by actively resisting the cultural oppression of their immediate environments, partaking in the civic life of their immediate surroundings. Furthermore, not only do they derive a personal creative benefit though their activities, but also, by encouraging (through online engagement and visibility) the interaction and participation of other Iranians, their actions serve to undermine the hierarchical creative oppression against which they struggle, pointing to a profound entanglement between on-/offline, 'mediated'/'unmediated' publics, and 'dutiful'/'actualising' modes of citizenship.

\section{Conclusions}

eliegregor says at 0:39:

Keep on playing Mouhammed! We are together...

— comment on 'I don't belong here', https://soundcloud.com/nils_frahm.

If citizenship represents the ability to improve and build upon aspects of civic life through proactive ways and means, then it also represents the ability to enact change upon those aspects through methods that are reactive, subversive, and resistant. Wellman and Castells's notion of 'networked individualism' and the idea of civic benefit may of course seem incompatible, insofar as Wellman's inherently individualistic theory seems at odds with notions of community and the collective. But what this paper has sought to argue is that it is 
precisely this individualism - a self-directed navigation through the networked publics of the contemporary digital landscape-that affords the user a route towards self-actualised versions of citizenship. As indicated by this terminology ('publics,' 'actualised'), these ideas resonate strongly with the work of boyd (2007) and Bennett (2008). It is precisely through the informal, transient interaction of users across geographic and cultural divides, and an engagement with alternative, transnational, virtual communities, that this individualism arises. Incorporating sociological perspectives on these digital interactions, and being receptive to the idea that attempts to enact change upon civic life might just as easily emerge through community disengagement as it can engagement, should be fundamental aspect of the study of creative citizenship. As such, the the sharing of what is essentially artistic_-sometimes simply entertainment-content, at least in the instances described herein, is the political act and an engagement in a political discourse. As we have seen, this can include cultural oppression, but so could might it also refer to cultural or geographical isolation, a lack of technological infrastructure, or a dearth of business opportunities. All of these mark opportunities for further research and consideration in this area. 


\section{References}

Anderson, Chris. 2012. Makers: The New Industrial Revolution. New York, NY: Crown Business.

Baym, Nancy. 1995. "The emergence of community in computer mediated communication.” In Cybersociety: Computer Mediated Communication and Community, edited by S. G. Jones, 138-163. Thousand Oaks, CA: Sage.

Baym, Nancy. 1998. “The emergence of on-line community." In: Cybersociety 2.0: Revisiting Computer Mediated Communication and Community, edited by S. G. Jones, 35-68. Thousand Oaks, CA: Sage.

Bennett, W. Lance. 2008. “Changing Citizenship in the Digital Age.” In: Civic Life Online: Learning How Digital Media Can Engage Youth, edited by W. L. Bennett. Cambridge, MA: The MIT Press.

Bennett, W. Lance, Chris Wells, and Deen Freelon. 2011. Communicating Civic Engagement: Contrasting Models of Citizenship in the Youth Web Sphere. Journal of Communication, 61(5), 835-856.

boyd, danah. 2007. Why Youth (Heart) Social Network Sites: The Role of Networked Publics in Teenage Social Life. In: MacArthur Foundation Series on Digital Learning - Youth, Identity, and Digital Media Volume (ed. David Buckingham). Cambridge, MA: MIT Press.

Castells, Manuel. 1990. The Informational City: A Framework for Social Change. Toronto: University of Toronto Press.

Castells, Manuel. 2000. The Rise of the Network Society. 2nd ed. Cambridge, MA: Blackwell.

Castells, Manuel. 2001. The Internet Galaxy: Reflections on the Internet, Business, and Society. Oxford: Oxford University Press.

Castells, Manuel. 2007. "Communication, Power, and Counter-power in the Network Society." International Journal of Communication, no. 1:238-266.

Castells, Manuel. 2009. Communication Power. Oxford: Oxford University Press.

Downes, Daniel M., and Richard Janda. 1998. "Virtual Citizenship." Canadian Journal of Law and Society 13(2): 27-61.

Elahi, Babak. 2011. Crossing Tehran Avenue: Digital and urban spaces in Tehran. Cultural Studies, 26(6), 956-981.

Freemuse. 2006a. "Gissoo Shakeri: “My voice is the voice of women who cannot sing'” Freemuse. Accessed July 20 2016. http://freemuse.org/archives/663.

Freemuse. 2006b. “No more download of music." Freemuse. Accessed July 20 2016. http://freemuse.org/ archives/763.

Freemuse. 2007. "Musician bypasses censorship on the internet." Freemuse. Accessed July 20 2016. http:// freemuse.org/archives/1028.

Freemuse. 2008. “About Freemuse”. Freemuse. Accessed July 20 2016. http://freemuse.org/archives/4. 
Harte, David. 2013. “'One Every Two Minutes': assessing the scale of hyperlocal publishing in the UK." JOMEC Journal, vol. 3.

Harte, David, Andy Williams, and Jerome Turner. 2014. “The Value of UK Hyperlocal Community News." Digital Journalism 3 (5): 1-24.

Jenkins, Henry. 2006. Convergence Culture: Where Old and New Media Collide. New York, NY: New York University Press.

Jenkins, Henry, Ravi Purushotma, Margaret Weigel, Katie Clinton and Alice J. Robison. 2006. Confronting the Challenges of a Participatory Culture: Media Education for the 21st Century.

Jenkins, Henry, Sam Ford, and Joshua Green. 2013. Spreadable Media: Creating Value and Meaning in a Networked Culture. New York, NY: New York University Press.

Jenkins, Henry, Mizuko Ito, and Danah Boyd. 2016. Participatory Culture in a Networked Era. Cambridge: Polity Press.

Kibby, Marjorie D. 2000. “Home on the page: a virtual place of music community." Popular Music 19 (1): 91-100.

Kruse, Holly. 2010. Local Identity and Independent Music Scenes, Online and Off. Popular Music and Society 33 (5): 625-639.

Levine, Faythe, and Cortney Heimerl. 2008. Handmade Nation: The Rise of DIY, Art, Craft and Design. New York, NY: Princeton Architectural Press.

Loader, Brian D., and Dan Mercea. 2011. "Networking Democracy? Social media innovations in participatory politics." Information, Communication and Society 14 (6): 757-769.

Lotan, Gilad, et al. 2011. The Revolutions Were Tweeted: Information Flows During the 2011 Tunisian and Egyptian Revolutions. International Journal of Communications, 5, 1375-1405.

Lysloff, René T. A. 2003. “Musical Community on the Internet: An On-Line Ethnography." Cultural Anthropology 18 (2): 233-263.

Mercea, Dan, Eleftheria Lekakis, and Paul G. Nixon. 2013. “Taking stock: A Meta-Analysis of the Virtual Public Sphere in Communication Journals." In Views from the Cloud: Politics, Citizens, and the Internet in Comparative Perspective, edited by P. G. Nixon and R. Rawal, 10-25. London: Routledge.

Mossberger, Karen. 2009. “Toward digital citizenship: addressing inequality in the information age." In Routledge Handbook of Internet Politics, edited by A. Chadwick and P. N. Howard, 173-185. Abingdon: Routledge.

Nooshin, Laudan. 2005. “Underground, Overground: Rock Music and Youth Discourses in Iran." Iranian Studies 38 (3): 463-494.

Nooshin, Laudan. 2008. “The Language of Rock: Iranian Youth, Popular Music, and National Identity." In Media culture and society in Iran: Living with globalisation and the Islamic State, edited by M. Semati, 69-93. New York, NY: Routledge. 
Papacharissi, Zizi. 2002. “The Virtual Sphere: The Internet as a public sphere." New Media Society 4 (1): 9-27.

Papacharissi, Zizi. 2008. “The Virtual Sphere 2.0: The Internet, the Public Sphere, and Beyond.” In Routledge Handbook of Internet Politics, edited by A. Chadwick and P. N. Howard, 230-245. Abingdon: Routledge.

Prior, Nick. 2008. “OK COMPUTER: Mobility, software, and the laptop musician.” Information, Communication \& Society 11 (7): 912-932.

Prior, Nick. 2010. "The rise of the new amateurs: Popular music, digital technology, and the fate of cultural production." In: Handbook of Cultural Sociology, edited by R. Hall, L. Grindstaff and M. Lo, 398-407. Abingdon: Routledge.

Raine, Lee and Wellman, Barry. 2012. Networked: The New Social Operating System. Cambridge, MA: MIT Press.

Rastovac, Heather. 2009. "Contending with Censorship: The Underground Music Scene in Urban Iran." intersections 10 (2): 59-82.

Reitov, Ole, ed. 2016. "Art Under Threat - FREEMUSE Annual Statistics on Censorship and Attacks on Artistic Freedom in 2015" Freemuse. <http://artsfreedom.org/wp-content/uploads/2016/02/FreemuseAnnual-Statistics-Art-Under-Threat-2015.pdf > [accessed 17 May 2016].

Roque, Ricarose, and Dasgupta, Sayamindu. 2011. Expressing, Engaging, Reacting: Civic Engagement in an Online Community of Young Creators. MIT: Center for Civic Media.

Sanders, Elizabeth B.-N., and Pieter J. Stappers. 2014. "Probes, toolkits and prototypes: three approaches to making in codesigning." CoDesign: International Journal of CoCreation in Design 10 (1): 5-14.

Shafaee, Seyed M. M. 2003. "Globalisation and Contradiction Between the Nation and the State in Iran: The Internet Case." Critique: Critical Middle Eastern Studies 12 (2): 185-95.

Shirky, Clay. 2008. Here Comes Everybody. London: Allen Lane.

Siamdoust, Nahid. 2017. Soundtrack of the Revolution: The Politics of Music in Iran. Stanford, CA: Stanford University Press.

Tapper, Joan, and Gale Zucker. 2011. Craft Activism: People, Ideas, and Projects from the New Community of Handmade and How You Can Join In. New York, NY: Random House.

Smith, John D., White, Nancy I., and Wenger, Etienne. Digital Habitats: Stewarding Technology for Communities. Portland, OR: CPsquare.

Tartousseih, Karim. 2011. "Virtual citizenship: Islam, culture, and politics in the digital age." Religion and Cultural Policy 17 (2): 198-208.

Thompson, John. 1995. The Media and Modernity. Stanford, CA: Stanford University Press.

Turkle, Sherry. 1995. Life on the Screen: Identity in the Age of the Internet. New York, NY: Simon and Schuster. 
Wellman, Barry. 1999. "From Little Boxes to Loosely-Bounded Networks: The Privatisation and Domestication of Community." In Sociology for the Twenty-First Century: Continuities and Cutting Edges, edited by J. L. Abu-Lughod, 94-114. Chicago, IL: University of Chicago Press.

Wellman, Barry. 2001. "Physical Place and Cyberplace: The Rise of Personalised Networking." International Journal of Urban and Regional Research 25 (2): 227-252.

Wellman, Barry. 2002. “Little Boxes, Glocalization, And Networked Individualism”. In Digital Cities II: Computational and ecological Approaches, edited by M. Tanabe, P. van den Besselaar, and T. Ishida, 11-25. Berlin: Springer-Verlag, 2002.

Wellman, Barry, Anabel Quan-Haase, Jeffrey Boase, Wenhong Chen, Keith Hampton, Isabel Isla de Diaz, Kakuko Miyata. 2006. "The Social Affordances of the Internet for Networked Individualism." Journal of Computer-Mediated Communication 8 (3). Online publication.

Waldron, Janice. 2009. "Exploring a virtual music 'community of practice': Informal music learning on the Internet." Journal of Music, Technology and Education 2 (2-3): 97-112.

Youssefzadeh, Ameneh. 2000. "The Situation of Music in Iran since the Revolution: The Role of Official Organizations." British Journal of Ethnomusicology 9 (2): 35-61. 